\title{
Waste Tire Pyrolysis: Influential Parameters and Product Properties
}

\author{
Ali Alsaleh • Melanie L. Sattler
}

Published online: 20 September 2014

(C) Springer International Publishing AG 2014

\begin{abstract}
Approximately 1.5 billion tires are produced globally each year with 300 million in the USA, which will all eventually become waste tires. Waste tires are excellent candidates for recovery of energy, as well as solid, liquid, and gaseous by-products, via pyrolysis: made predominantly from the petroleum product rubber, they have a high heating value, as well as high volatile content and medium sulfur content. This paper reviews previous research on tire pyrolysis, and in particular identifies factors affecting yield and product composition. Properties of produced oil, gases, and char are summarized, and future research studies are recommended.
\end{abstract}

Keywords Tires $\cdot$ Waste $\cdot$ Pyrolysis $\cdot$ Energy $\cdot$ Alternative energy

\section{Introduction}

Approximately 1.5 billion tires are produced each year globally and 300 million in the USA, which will eventually become waste tires [1]. Tire piles often provide breeding grounds for pests and insects such as mosquitoes, because their shape and impermeability allow them to hold water for extended periods. Waste tire stockpiles are difficult to ignite; however, once ignited, tires burn very hot and are very difficult to extinguish, resulting in considerable release of air pollutants, including particulates [2].

In $2011,82 \%$ of the waste tire tonnage in the US was beneficially re-used, with the top uses being tire-derived fuel

A. Alsaleh · M. L. Sattler $(\bowtie)$

Department of Civil Engineering, University of Texas at Arlington,

Box 19308, Arlington, TX 76019, USA

e-mail: sattler@uta.edu

A. Alsaleh

e-mail: ali3738@yahoo.com and ground rubber [2]. However, $18 \%$ (696,000 tons, or 59 million tires), were still disposed of in landfills or dumped illegally, where they could harbor pests or lead to difficult-tocontrol fires. Such disposal also represents loss of a high-value material $[3-5,6 \bullet]$.

The negative impacts of landfill disposal or illegal dumping of tires can be minimized by recovering constituent chemicals and energy from these tires using available technologies [7]. Made predominantly from the petroleum product rubber, they have a high heating value, as well as high volatile content and medium sulfur content, properties which make them excellent candidates for pyrolysis, which can be used to recover energy and by-products $[6 \bullet, 8,9]$.

\section{Tire Materials}

Over one hundred different compounds comprise tires, depending on the manufacturer and use. Basically, tires are made of rubber (60-65 wt. \%), carbon black (25-35 wt. \%), fillers (3 wt. \%), and accelerators. Rubber is comprised of elastomeric polymers characterized by a network structure that can deform short-term under the influence of external forces. A blend of natural rubber from the Heave tree and synthetic rubber derived from petroleum-based products is used. Carbon black is used to strengthen the rubber and enable it to resist abrasion. To make the rubber softer and more workable, fillers are added (a combination of aromatic, naphthenic, and paraffinic organics) $[10 \bullet]$.

\section{Reasons for Difficulties in Tire Management}

Several factors make waste tires very difficult to manage or to recycle: 
1. Tires are designed to withstand harsh conditions such as exposure to ozone (the most damaging factor for rubber), friction, light, and bacteria. This means they do not degrade in landfills; the tire lifetime in a landfill is considered to be between 80 and 100 years [11].

2. Whole tires have a low bulk density; around $75 \%$ of their volume is empty space. This means they take up a large volume in a landfill.

3. The fact that tires are thermoset polymers means that they cannot be melted and separated into their chemical components [10•].

\section{The Pyrolysis Process}

Pyrolysis involves heating a feedstock to temperatures $>400{ }^{\circ} \mathrm{C}$ without oxygen in order to volatilize and decompose the feedstock, producing oil, gas, and char [10॰]. The oil resulting from pyrolysis may be used directly as a fuel, upgraded to a higher quality fuel, or used to produce chemicals. The gases typically consist of $\mathrm{C} 1-\mathrm{C} 4$ hydrocarbons and hydrogen with a high heating content, so that the gases can serve as a fuel for the pyrolysis process. The solid char consists of carbon black filler along with pyrolysis char $[12 \bullet]$.

\section{Pyrolysis Reactors}

The most common pyrolysis reactors include fixed-bed, rotary kiln, and fluidized-bed. Fixed bed reactors (FBR) are usually used for slow pyrolysis in a batch process characterized by low heating rates, long solid and vapor residence times (minutes to hours), and often low temperature [10•]. FBRs contain the catalyst, typically in pellet form, in a fixed location. A major drawback is limited access to the catalyst surface area [13].

A rotary kiln is a sheet-steel cylinder, lined with refractory material to protect the steel from high temperatures, and slightly inclined $\left(1^{\circ}-10^{\circ}\right)$ to advance the waste material. For a given waste material, the system may be optimized in terms of speed of rotation, degrees of filling, and sizes of particles. Rotary kilns also allow a wide variety of sizes and types of material to be used [14].

Kaminsky, et al., have performed several studies of fluidized bed tire pyrolysis [15-19]. Fluidized beds are typically used to perform fast pyrolysis (reaction time of milliseconds to seconds); fast pyrolysis requires small particle sizes [10•]. Fluidized bed reactors have been studied at laboratory scale with $1 \mathrm{~kg}$ /hour throughput, technical scale with $30 \mathrm{~kg} / \mathrm{hour}$ throughput, and pilot scale with $200 \mathrm{~kg} /$ hour throughput [12•]. Pyrolysis gas provides heat to the bed of quartz sand via radiant heat tubes; the fluidized bed is thus heated indirectly to typical temperatures of $500{ }^{\circ} \mathrm{C}-780{ }^{\circ} \mathrm{C}$. The product gas, preheated to $400{ }^{\circ} \mathrm{C}$, is used as the fluidizing gas.

\section{Influence of Various Parameters on the Yield of Pyrolysis Products from Waste Tires}

Temperature is the predominant factor influencing the distribution of gas, liquid, and solid phase pyrolysis products and their physical/chemical properties [10•]. Other influential factors include heating rate, particle size, feedstock composition, pyrolysis time/tire residence time, carrier gas flow rate/volatiles residence time, atmospheric pressure and type (including presence of steam in the carrier gas), and presence of a catalyst $[10 \bullet, 20]$. Martinez, et al. (2013), provide an exhaustive review of studies concerning the influence of these parameters [10 ]. Salient effects of these factors are highlighted here.

\section{Temperature}

The pyrolysis temperature must be high enough to thermally degrade the tires; however, higher temperatures and long gas residence times in the reactor hot zone can volatilize the oil to gas $[12 \cdot, 21]$. Thus, an optimal temperature exists for maximizing oil production. Maximizing oil production is typically the goal, since it is the most valuable of the products.

Table 1 summarizes a number of studies that have investigated the influence of temperature on oil yield from tire pyrolysis. Across the studies, optimal temperatures for oil production range from $425^{\circ} \mathrm{C}$ to $720^{\circ} \mathrm{C}$, and maximum yields range from $38 \%$ to $60 \%$. This considerable variability in optimal temperatures and maximum yields is likely due to differences in heating rate, gas residence time, reactor type, tire mass flow rate, and tire particle size. These secondary factors can particularly influence secondary reactions, which convert liquid compounds to gas phase or gas phase to solid phase [10•]. One of the recommendations for future research is to build a regression model to predict oil yield as functions of temperature, heating rate, type of reactor, tire mass flow rate, tire particle size, and any interaction terms.

\section{Heating Rate}

Increasing the heating rate increases the degradation rate, and also affects the temperature at which maximum volatilization starts and stops [10 ]. Higher heating rates lead to higher temperatures, which can lead to more secondary reactions, which can produce more gas-phase products [28]. The nature of the secondary reactions can impact the composition of the gas as well as the liquid. Heating rate, as well as temperature and particle size, can produce different impacts depending on 
Table 1 Summary of studies of the impact of temperature and heating rate on oil yield

\begin{tabular}{|c|c|c|c|c|c|c|c|}
\hline Authors (Year) & Reactor type & Tire mass & $\begin{array}{l}\text { Temp. } \\
\text { range } \\
\left({ }^{\circ} \mathrm{C}\right)\end{array}$ & $\begin{array}{l}\text { Heating } \\
\text { rate } \\
\left({ }^{\circ} \mathrm{C} / \mathrm{min}\right)\end{array}$ & $\begin{array}{l}\text { Optimal temp. } \\
\text { for oil } \\
\text { production }\left({ }^{\circ} \mathrm{C}\right)\end{array}$ & $\begin{array}{l}\text { Max. oil } \\
\text { yield } \\
\text { (wt. \%) }\end{array}$ & Other notes \\
\hline Williams, et al. (1990), [22] & Fixed bed batch & $50 \mathrm{~g}$ & $300-720$ & 5 to 80 & $600-720$ & $54-58.8$ & $\begin{array}{l}\text { At } 300{ }^{\circ} \mathrm{C} \text {, the tires degraded } \\
\text { very little. }\end{array}$ \\
\hline $\operatorname{Kar}(2011),[6 \bullet]$ & Fixed bed batch & $10 \mathrm{~g}$ & $375-500$ & 10 & 425 & 60 & $\begin{array}{l}\text { Observed increase in gas } \\
\text { yield and decrease in oil } \\
\text { yield above } 425^{\circ} \mathrm{C} \text {. }\end{array}$ \\
\hline Aydın and Ilk1lıc (2012), [23] & Fixed bed batch & N/A & $400-700$ & N/A & 500 & 40 & $\begin{array}{l}\text { Varying nitrogen flow rate } \\
\text { did not substantially } \\
\text { impact oil yield }\end{array}$ \\
\hline $\begin{array}{l}\text { Aylon, et al. }(2008,2010) \text {, } \\
{[8,24]}\end{array}$ & Rotary kiln & 3.5 to $8.0 \mathrm{~kg} / \mathrm{h}$ & $600-800$ & N/A & 600 & 48.4 & $\begin{array}{l}\text { Optimal tire mass flow rate } \\
\text { was } 8 \mathrm{~kg} / \mathrm{h} \text {. }\end{array}$ \\
\hline Galvagno, et al. (2002), [4] & $\begin{array}{l}\text { Pilot scale rotary } \\
\text { kiln }\end{array}$ & $4.8 \mathrm{~kg} / \mathrm{h}$ & $450-700$ & N/A & 550 & 38.1 & \\
\hline Li, et al. (2004), [25] & Rotary kiln & N/A & $450-650$ & N/A & 500 & 45.1 & \\
\hline Gonzalez, et al. (2001), [7] & Vacuum & N/A & $375-500$ & 10 & 425 & 60 & \\
\hline $\begin{array}{l}\text { Williams and Brindle } \\
\text { (2003), [26] }\end{array}$ & $\begin{array}{l}\text { Lab-scale } \\
\quad \text { fluidized bed }\end{array}$ & $220 \mathrm{~g} / \mathrm{h}$ & $450-600$ & N/A & 450 & 55 & \\
\hline Dai, et al. (2001), [27] & $\begin{array}{l}\text { Lab-scale } \\
\quad \text { fluidized bed }\end{array}$ & N/A & $360-810$ & N/A & 450 & 52 & $\begin{array}{l}\text { Smaller tire particles } \\
\text { increased oil yield; longer } \\
\text { residence times in the hot } \\
\text { zone decreased oil yield. }\end{array}$ \\
\hline
\end{tabular}

values of other parameters [10•]. Heating rate also impacts the time to complete pyrolysis and energy required: lower heating rates necessitate longer residence times, but require less energy [29]. Heating rate is linked to reactor type, with certain reactor types producing higher heating rates [10•, 24].

\section{Particle Size}

For small particles, the temperature is assumed to be uniform throughout the particle; for larger particles, the slower heating of the interior means that the pyrolysis occurs at a lower temperature [10•]. However, small particles are often completely converted to liquid and gas phase, whereas for larger particles, the interior remains in the solid phase due to the lower temperature [10॰]. If maximizing oil yield is an important objective, then smaller particles are desirable [27, 30].

Dai, et al. (2001), for example, found that $0.32 \mathrm{~mm}$ particles produced more liquid-phase product (around 50 wt. \%), than larger $0.8 \mathrm{~mm}$ diameter particles (around $40 \%$ ); the smaller particles also produced more gas-phase product, but reduced char [27]. Smaller tire particles increased oil yield. If the same conversion of large particles is desired that occurs with smaller particles, the residence time of the tire particles inside the reactor must be increased; this increases the required reactor volume, and thus increases capital costs [10•]. An increase in temperature or heating rate could offset the need for a larger reactor volume, but with an influence on product distribution.

\section{Feedstock Composition}

A number of studies have found differences in aromatic content of pyrolysis oil based on original tire composition, particularly the natural and synthetic rubber content [10•, 31-35]. Ucar, et al. (2005), for example, found that truck tires, with a natural rubber content of $51 \mathrm{wt}$. \%, yielded 15.4 vol. \% aromatic content; passenger car tires, with a lower natural rubber content of $35 \mathrm{wt}$ \%, produced a higher aromatic content of 41.5 vol. \% [32]. Seidelt, et al. (2006), found that natural rubber produced primarily xylene and isoprene dimmer, whereas styrene-butadiene rubber yielded ethylbenzene, styrene, and cumene [36]. Variations in liquid yield and sulfur content have also been observed based on the particular feedstock: Ucar, et al. (2005), found that truck tires, with higher natural rubber content, generated a greater amount of oil (55.6 wt. \%) with lower sulfur content (0.83 wt. \%) compared to passenger car tires, which generated 47.4 wt. \% oil with 1.35 wt. \% sulfur [32]. Hence, passenger car tires, with higher synthetic rubber content, tend to produce oil with greater value for chemical production due to its higher aromatic content. Truck tires, with higher natural rubber content, tend to produce oil with greater potential as a vehicle fuel, due to its lower sulfur content.

\section{Pyrolysis Time/Tire Residence Time}

Pyrolysis time is related to particle size: in general, larger particles require longer residence times to achieve the same 
degree of conversion [10•]. Longer residence times require a larger reactor, with larger capital costs. Pyrolysis time is also linked to heating rate, with lower heating rates requiring longer pyrolysis times [10 $]$. Finally, several researchers have found a time-temperature trade-off: higher temperatures needing shorter tire residence times, and lower temperatures require longer residence times [29, 37].

\section{Carrier gas Flow Rate/Volatiles Residence Time}

An increase in carrier gas flow rate carries the gaseous products away more quickly, decreasing the volatile product's residence time [16]. A longer volatile residence time means that secondary reactions are more likely to occur, which can decrease oil yield if liquid phase compounds convert to gas phase. Thus, increasing carrier gas flow rate has been found to increase oil yield [24, 38, 39].

\section{Atmospheric Pressure}

Increasing atmospheric pressure has been found to increase oil viscosity [35]. On the other hand, reduced pressure (often associated with vacuum pyrolysis), has been found to reduce secondary reactions in the gas phase, by reducing volatiles residence time; this would tend to increase oil yield [10•, 40-44]. Also, reducing secondary reactions can reduce gas deposition onto the solid char surface, which can make the char more valuable as an activated carbon adsorbent, with higher surface area and increased reactivity [10॰]. Decreasing process pressure may also decrease process temperature ( $\mathrm{PV}=\mathrm{nRT}$, according to the ideal gas law); decreasing process temperature decreases energy demand [10॰].

\section{Presence of Steam in Carrier Gas}

In addition to producing oil for transportation purposes and chemical products, tire pyrolysis can produce hydrogen, which can be used as a fuel. Mastral, et al. (2002), showed that $1 \mathrm{~kg}$ of waste tire could yield $0.158 \mathrm{~kg} \mathrm{of}_{2}$, according to the following Eqs. 1 and $2[12 \cdot, 44]$ :

$$
\mathrm{C}_{\mathrm{n}} \mathrm{H}_{\mathrm{m}}+\mathrm{nH}_{2} \mathrm{O} \rightarrow \mathrm{nCO}+(\mathrm{n}+\mathrm{m} / 2) \mathrm{H}_{2}
$$

$\mathrm{CO}+\mathrm{H}_{2} \mathrm{O} \rightarrow \mathrm{CO}_{2}+\mathrm{H}_{2}$

In Eq. (1), $\mathrm{C}_{\mathrm{n}} \mathrm{H}_{\mathrm{m}}$ represents carbohydrate vapors released during tire pyrolysis, and $\mathrm{H}_{2} \mathrm{O}$ is from added steam. If more steam is added, the hydrogen yield increases via the hydrocarbon steam reforming reaction. Addition of water also slows down the rate of the catalyst deactivation by coking, according to the steam gasification reaction (Eq. 3):

$\mathrm{C}+\mathrm{H}_{2} \mathrm{O} \rightarrow \mathrm{CO}+\mathrm{H}_{2}$

Post-pyrolysis catalysis at higher temperatures via nickelbased catalysis can be used to form hydrogen from waste tires $[10 \bullet, 45,46 \bullet, 47]$. Elbaba, et al. (2010), pyrolyzed tires in a fixed bed at $500{ }^{\circ} \mathrm{C}$, and then passed the gases over a nickel based $\mathrm{Ni}-\mathrm{Mg}-\mathrm{Al}$ catalyst at $800^{\circ} \mathrm{C}$, in the presence of steam [44].

\section{Catalyst}

Catalysts can be used to improve pyrolysis rate, oil quality, oil yield, and yields of compounds such as aromatics for chemical production. To enhance pyrolysis rate and oil quality, Dung, et al. (2009), used ITQ-21 and ITQ-24 as additives to commercial HMOR zeolite for catalytic pyrolysis of waste tires $[6 \bullet, 48]$. They showed that the catalyst-to-tire ratio impacts the yield of gasoline, kerosene, and asphaltenes in pyrolytic oils. Kar (2011), heated expanded perlite (a volcanic rock of primarily silica and alumina), to $850{ }^{\circ} \mathrm{C}-1000{ }^{\circ} \mathrm{C}$ to create a porous catalyst support; metals were then added to the support to serve as catalysts $[6 \bullet, 12 \cdot]$. A perlite to waste tire ratio of 0.10 increased oil yield from 60.0 to $65.1 \mathrm{wt}$. \%. The resulting fuel heating value, density, viscosity, and elemental composition were comparable to regular petroleum fuels. Ates, et al. (2005), also boosted both oil yield and oil aromatic content using 10 wt. \% activated alumina [49]. Williams and Brindle (2003), boosted concentrations of aromatics, as well as naphthalenes and alkylated naphthalenes, using $\mathrm{Y}$ zeolite catalyst (CBV-400 and CBV-780), and zeolite ZSM$5[12 \cdot, 26]$.

\section{Properties of Waste Tire Pyrolysis Products}

\section{Oil Properties}

Pyrolysis oil typically has medium viscosity and heating value around $40 \mathrm{MJ} / \mathrm{kg}[12 \bullet, 43]$. Over 100 compounds have been identified in tire pyrolysis oil; most of these are $\mathrm{C}_{5}-\mathrm{C}_{20}$ hydrocarbons which include polyaromatic hydrocarbons (PAHs), polyaromatic nitrogen hydrocarbon (PANH), and polyaromatic sulfur hydrocarbons (PASHs) [12 • 18, 25, 27, 50-55]. Predominant aromatics include benzene, toluene, xylenes, styrene, limonene, and indene [12•]. The most abundant aliphatics are straight chain alkanes (C6-C37), with lesser 
amounts of alkenes [12•]. Williams (2013), compared properties of tire pyrolysis oil found by a variety of studies [12•].

The light fraction of pyrolysis oil yields refined chemicals, such as BTEX and styrene, and the heavy fraction can enhance asphalt properties. The petrochemical industry can use the light olefins and aromatics in synthesis of chemicals (isoprene and 1, 3-butadiene), needed for tire manufacturing. Pyrolytic oils have burned successfully in test furnaces and diesel engines (blended with diesel fuel) [12•].

Aydın and Ilkılıc (2012), studied the impact of pyrolysis temperature on resulting oil sulfur content [23]. They found lowest sulfur content in pyrolysis oil at an intermediate pyrolysis temperature of $550{ }^{\circ} \mathrm{C}$, with higher sulfur content as temperatures were reduced to $400{ }^{\circ} \mathrm{C}$ or increased to $650{ }^{\circ} \mathrm{C}$. Cunliffe and Williams (1998), found higher sulfur content (1.4 wt. \%) of oils produced at lower pyrolysis temperatures $\left(450{ }^{\circ} \mathrm{C}\right.$ and $475^{\circ} \mathrm{C}$ ), compared to higher temperatures $[12 \cdot, 38]$.

\section{Char Properties}

The char fraction of tire pyrolysis products ranges from $22 \mathrm{wt}$. $\%$ to 49 wt. $\%$, with usual values of $38-40$ wt. $\%$ [12•]. The char yield is high due to the carbon black contained in the original tire. Char is generally composed of carbon, along with inorganics from tire manufacture (e.g., $\mathrm{Zn}, \mathrm{Ca} \mathrm{Si}$ ), with exact composition depending on pyrolysis conditions and tire composition [10•]. Several studies have attempted to increase char commercial value by creating higher quality carbon black, or using steam or $\mathrm{CO}_{2}$ to create activated carbons with high surface areas $\left(1000 \mathrm{~m}^{2} / \mathrm{g}\right)[12 \bullet]$.

\section{Gas Properties}

Williams (2013), compared gases produced from waste tire pyrolysis according to a variety of studies [12•]. Major gas constituents include hydrogen $\left(\mathrm{H}_{2}\right)$, methane $\left(\mathrm{CH}_{4}\right)$, ethane $\left(\mathrm{C}_{2} \mathrm{H}_{6}\right)$, ethene $\left(\mathrm{C}_{2} \mathrm{H}_{4}\right)$, propane $\left(\mathrm{C}_{3} \mathrm{H}_{8}\right)$, propene $\left(\mathrm{C}_{3} \mathrm{H}_{6}\right)$, butane $\left(\mathrm{C}_{4} \mathrm{H}_{10}\right)$, butene $\left(\mathrm{C}_{4} \mathrm{H}_{8}\right)$, butadiene $\left(\mathrm{C}_{4} \mathrm{H}_{6}\right)$, carbon dioxide $\left(\mathrm{CO}_{2}\right)$, carbon monoxide $(\mathrm{CO})$, and hydrogen sulfide $\left(\mathrm{H}_{2} \mathrm{~S}\right)$. The exact gas composition depends on the specific rubbers used in tire manufacture, as well as pyrolysis temperature. Overall gas yield increases with higher pyrolysis temperature, as more oil converts to vapor. Raising pyrolysis temperature can also increase hydrogen production, which is desirable if that is a goal of the process [18].

\section{Recommendations for Future Research}

Building a regression model to predict oil yield as functions of: type of reactor, temperature, heating rate, particle size, feedstock composition, pyrolysis time/tire residence time, carrier gas flow rate/volatiles residence time; atmospheric pressure and type (including presence of steam in the carrier gas), presence of a catalyst, and any interaction terms would be useful. Heating rate, as well as temperature and particle size, can produce different impacts depending on values of other parameters; this indicates that interaction terms are likely important. The pyrolysis variables impact the pyrolysis product distribution and composition of gas, liquid, and solidphase products in a complex way. Such a regression model would help illuminate these impacts, and relationships among the variables.

A future study directly comparing oil yields of various reactor types (batch/fixed bed, rotary kiln, and fluidized bed), for the same tire feedstock is recommended. The impact of heating rate on oil yield should be studied in greater detail. Additional catalysts for improving oil yield can be investigated, and promising pilot-scale systems can be tested.

\section{Conclusions}

Made predominantly from petroleum rubber, waste tires are excellent candidates for pyrolysis to recover energy and byproducts. Temperature is the predominant factor influencing the distribution of gas, liquid, and solid phase pyrolysis products, and their physical/chemical properties. Other influential factors include heating rate, particle size, feedstock composition, pyrolysis time/tire residence time, carrier gas flow rate/volatiles residence time, presence of steam in the carrier gas, and presence of a catalyst.

Pyrolytic oils from waste tires, with typical heating value around $40 \mathrm{MJ} / \mathrm{kg}$, have been burned successfully in test furnaces and diesel engines. Pyrolysis oils can also yield useful chemicals for the petrochemical industry, including light olefins and aromatics. Solid-phase pyrolysis char can be used to created carbon black or activated carbon for pollutant removal. Gases produced, including hydrogen and various hydrocarbons, can be used as a fuel for the pyrolysis process.

In terms of future research, building a regression model to predict oil yield as functions of temperature, heating rate, type of reactor, tire particle size, and any interaction terms would be useful.

\section{Compliance with Ethics Guidelines}

Conflict of Interest Ketwalee Kositkanawuth, Melanie L. Sattler, and Brian Dennis declare no conflict of interest.

Human and Animal Rights and Informed Consent This article does not contain any studies with human or animal subjects performed by any of the authors. 


\section{References}

Papers of particular interest, published recently, have been highlighted as:

- Of importance

1. US Environmental Protection Agency. "Wastes - Resource Conservation - Common Wastes and Materials - Scrap Tires: Basic Introduction.” http://www.epa.gov/wastes/conserve/ materials/tires/basic.htm. Accessed 20 March 2014.

2. Pollution Prevention Resource Exchange. P2 Infohouse: a comprehensive pollution prevention reference collection. http://infohouse. p2ric.org/. Accessed March 2014.

3. Rubber Manufacturers Association. "2011 US Scrap Tire Market Summary." http://www.rma.org/download/scrap-tires/marketreports/US_STMarket2011.pdf. Accessed 15 June 2014.

4. Galvagno S, Casu S, Casabianca T, Calabrese A, Cornacchia G. Pyrolysis process for the treatment of scrap tires: preliminary experimental results. Waste Manag. 2002;22:917-23.

5. Boxiong S, Chunfei W, Cai L, Binbin G, Rui W. Pyrolysis of waste tires: the influence of USY catalyst/tire ratio on products. J Anal Appl Pyrol. 2007;78:243-9.

6. Kar Y. Catalytic pyrolysis of car tire waste using expanded perlite. Waste Manag. 2011;31(8):1772-82. Study identifies a pyrolysis catalyst that increased oil yield by $5 \%$.

7. Shah J, Jan MR, Mabood F. Catalytic pyrolysis of waste tire rubber into hydrocarbons via base catalysts. Iran J Chem Chem Eng. 2008;27:103-9.

8. Aylon E, Fernandez-Colino A, Murillo R, Navarro MV, Garcia T, Mastral AM. Valorisation of waste tire by pyrolysis in a moving bed reactor. Waste Manag. 2010;30:1220-4.

9. Gonzalez JF, Encinar JM, Canito JL, Rodriguez JJ. Pyrolysis of automotive tire waste influence of operating variables and kinetic study. J Anal Appl Pyrolysis. 2001;58-59:667-83.

10. Martínez JD, Puy N, Murillo R, García T, Navarro MV, Mastral AM. Waste tire pyrolysis - a review. Renew Sust Energ Rev. 2013;23:179-213. Excellent review of tire pyrolysis studies concerning factors impacting distribution of gas, liquid, and solid phase pyrolysis products and their physical/ chemical properties.

11. European Tyre and Rubber Manufacturers' Association. "Recycling of ELTs in civil engineering applications." http:// www.etrma.org/tyres/ELTs/recovery-routes-and-trends/materialrecovery. Accessed 19 June 14.

12. Williams PT. Pyrolysis of waste tyres: a review. Waste Manag. 2013;33(8):1714-28. Good assimilation of tire pyrolysis oil property data from various studies, as well as gas composition data.

13. US Department of Energy, National Energy Technology Lab. "Fractionation of Organics from Air Particulates with Subcritical Water." http://www.netl.doe.gov/File\%20Library/Research/Coal/ ewr/air-quality-research/A053104_Final-Report_1.PDF. Accessed on 19 June 2014.

14. Zajec L. Slow pyrolysis in a rotary kiln reactor: Optimization and experiment. Master's Thesis, The School for Renewable Energy Science, in affiliation with University of Iceland and University of Akureyri, Feb. 2009, http://skemman.is/stream/get/1946/7005/ 17751/1/Luka Zajec.pdf. Accessed 14 April 2014.

15. Kaminsky W. Thermal recycling of polymers. J Anal Appl Pyrolysis. 1985;8:439-48.

16. Kaminsky W. Chemical recycling of mixed plastics by pyrolysis. Adv Polym Technol. 1995; 14:337.
17. Kaminsky W, Mennerich C. Pyrolysis of synthetic tire rubber in a fluidised- bed reactot ro yield 1,3-butadiene, stirene and carbon black. J Anal Appl Pyrolysis. 2001;58:803-11.

18. Kaminsky W, Mennerich C, Zhang Z. Feedstock recycling of synthetic and natural rubber by pyrolysis in a fluidized bed. $\mathrm{J}$ Anal Appl Pyrolysis. 2009;85:334-7.

19. Kaminsky W, Predel M, Sadiki A. Feedstock recycling of polymers by pyrolysis in a fluidised bed. Polym Degrad Stab. 2004;85:104550 .

20. Murillo R, Aylón E, Navarro MV, Callén MS, Aranda A, Mastral AM. The application of thermal processes to valorise waste tyre. Fuel Processing Technology. 2006;87:143-7.

21. Gašparovič L, Šugár L, Jelemenský L, Markoš J. Catalytic gasification of pyrolytic oil from tire pyrolysis process. Chem Pap. 2013;67(12):1504-13.

22. Williams PT, Besler S, Taylor DT. The pyrolysis of scrap automotive tires. Fuel. 1990;69:1474-82.

23. Aydın H, Ilkılıc C. Optimization of fuel production from waste vehicle tires by pyrolysis and resembling to diesel fuel by various desulfurization methods. Fuel. 2012;102:605-12.

24. Aylón E, Fernández-Colino A, Navarro MV, Murillo R, García T, Mastral AM. Waste tire pyrolysis: comparison between fixed bed reactor and moving bed reactor. Ind Eng Chem Res. 2008;47:4029-33.

25. Li A, Hu H, Fang Y, Liu H, Yu R, Luo G, et al. The fate of sulfur during rapid pyrolysis of scrap tires. Chemosphere. 2014;97:102-7.

26. Williams PT, Brindle AJ. Aromatic chemicals from the catalytic pyrolysis of scrap tires. J Anal Appl Pyrolysis. 2003;67:143-64.

27. Dai X, Yin X, Wu C, Zhang W, Chen Y. Pyrolysis of waste tires in a circulating fluidized-bed reactor. Energy. 2001;26:385-99.

28. Senneca O, Salatino P, Chirone R. A fast heating-rate thermogravimetric study of the pyrolysis of scrap tyres. Fuel. 1999;78:157581.

29. Cheung K-Y, Lee K-L, Lam K-L, Chan T-Y, Lee C-W, Hui C-W. Operation strategy for multi-stage pyrolysis. J Anal Appl Pyrolysis. 2011;91:165-82.

30. Barbooti MM, Mohamed TJ, Hussain AA, Abas FO. Optimization of pyrolysis conditions of scrap tires under inert gas atmosphere. J Anal Appl Pyrolysis. 2004;72:165-70.

31. Kyari M, Cunliffe A, Williams PT. Characterisation of oils, gases and char in relation to the pyrolysis of different brands of scrap automotive tires. Energy Fuel. 2005;19:1165-73.

32. Ucar S, Karagoz S, Ozkan AR, Yanik J. Evaluation of two different scrap tires as hydrocarbon source by pyrolysis. Fuel. 2005;84: 1884-92.

33. Roy C, Darmstadt H, Benallal B, Amen-Chen C. Characterization of naphtha and carbon black obtained by vacuum pyrolysis of polyisoprene rubber. Fuel Process Technol. 1997;50:87-103.

34. Lopez G, Olazar M, Amutio M, Aguado R, Bilbao JA. Influence of tire formulation on the products of continuous pyrolysis in a conical spouted bed reactor. Energy Fuel. 2009;23:5423-31.

35. Buekens AG. Some observations on the recycling of plastics and rubber. Conserv Recycl. 1977;1(3-4):247-71.

36. Seidelt S, Muller-Hagedorn M, Bockhorn H. Description of tire pyrolysis by thermal degradation behaviour of main components. J Anal Appl Pyrolysis. 2006;75:11-8.

37. Olazar M, Lopez G, Arabiourrutia M, Elordi G, Aguado R, Bilbao J. Kinetic modelling of tyre pyrolysis in a conical spouted bed reactor. J Anal Appl Pyrolysis. 2008;81:127-32.

38. Cunliffe AM, Williams PT. Composition of oils derived from the batch pyrolysis of tires. J Anal Appl Pyrolysis. 1998;44(3):131-52.

39. Islam MR, Haniu H, Beg MRA. Liquid fuels and chemicals from pyrolysis of motorcycle tire waste: product yields, compositions and related properties. Fuel. 2008;87:3112-22.

40. Li S-Q, Yao Q, Chi Y, Yan J-H, Cen K-F. Pilot-scale pyrolysis of scrap tires in a continuous rotary kiln reactor. Ind Eng Chem Res. 2004;43:5133-45 
41. Zhang X, Wang T, Ma L, Chang J. Vacuum pyrolysis of waste tires with basic additives. Waste Manag. 2008;28:2301-10.

42. Scheirs J. Overview of commercial pyrolysis processes for waste plastics. In: Scheirs J, Kaminsky W, editors. Feedstock recycling and pyrolysis of waste plastics: converting waste plastics into diesel and other fuels. New York: John Wiley \& Sons; 2006. p. 383-433.

43. Roy C, Labrecque B, Caumia B. Recycling of scrap tires to oil and carbon black by vacuum pyrolysis. Resour Conserv Recycl. 1990;4:203-13.

44. Mastral AM, Murillo R, Garcia T, Navarro MV, Callen MS, Lopez JM. Study of the viability of the process for hydrogen recovery from old tire oils. Fuel Process Technol. 2002;75:185-99.

45. Elbaba I, Wu C, Williams PT. Catalytic pyrolysis-gasification of waste tire and tire elastomers for hydrogen production. Energy Fuel. 2010;24:3928-35.

46. Elbaba I, Wu C, Williams PT. Hydrogen production from the pyrolysis- gasification of waste tires with a nickel/cerium catalyst. Int J Hydrog Energy. 2011;36:6628-37. Study important in terms of optimizing tire pyrolysis for hydrogen production.

47. Elbaba I, Williams PT. Two-stage pyrolysis-catalytic gasification of waste tires: influence of process parameters. Appl Catal B Environ. 2012; 125:136-43.
48. Dung NA, Mhodmonthin A, Wongkasemjit S, Jitkarnka S. Effects of ITQ- 21 and ITQ-24 as zeolite additives on the oil products obtained from the catalytic pyrolysis of waste tire. J Anal Appl Pyrol. 2009;85:338-44.

49. Ates F, Pütün AE, Pütün E. Fixed bed pyrolysis of Euphorbia rigida with different catalysts. Energ Convers Manag. 2005;46:421-32.

50. Kebritchi A, Firoozifar H, Shams K, Jalali-Arani A. Effect of pre devulcanization and temperature on physical and chemical properties of waste tire pyrolytic oil residue. Fuel. 2013;112:319-25.

51. Williams P, Bottrill RP. Sulfur-polycyclic aromatic hydrocarbons in tire pyrolysis oil. Fuel. 1995;74(5):736-42.

52. Conesa JA, Martín-Gullón I, Font R, Jauhiainen J. Complete study of the pyrolysis and gasification of scrap tires in a pilot plant reactor. Environ Sci Technol. 2004;38:3189-94.

53. Laresgoiti MF, Caballero BM, De Marco I, Torres A, Cabrero MA, Chomon MJJ. Characterization of the liquid products obtained in tire pyrolysis. J Anal Appl Pyrolysis. 2004;71:917-34.

54. Olazar M, Aguado R, Arabiourrutia M, Lopez G, Barona A, Bilbao J. Catalyst effect on the composition of tire pyrolysis products. Energy Fuel. 2008;22:2909-16.

55. Banar M, Akyıldız V, Ozkan A, Cokaygil Z, Onay O. Characterization of pyrolytic oil obtained from pyrolysis of TDF (Tire Derived Fuel). Energy Convers Manag. 2012;62:22-30. 